\title{
A Little Puzzle about a Piece and a Puddle
}

\author{
Mahrad Almotahari
}

Imagine Descartes's study. On a table next to his armchair there's a small, solid piece of wax-the handiwork of a local Parisian craftsman, from whom it was purchased. Now imagine that Descartes melts the whole thing, thus forming a single cohesive wax puddle.

Two equally compelling lines of thought suggest themselves:

Thesis. The puddle of wax was made by Descartes, but the initial piece of solid wax wasn't. Furthermore, the puddle was made by melting the initial piece of solid wax, while the initial piece of solid wax wasn't made by melting the initial piece of solid wax. Finally, Descartes didn't purchase the puddle of wax, but he did purchase the initial piece of wax. Plausibly, then, the initial piece of wax is distinct from the puddle of wax.

Antithesis. The puddle of wax is a liquified piece of wax, and a liquified piece of wax is a piece of wax-a piece of wax now in liquid form. The piece of wax now in liquid form wasn't made by Descartes (though he is responsible for its liquid form), and Descartes did purchase the piece of wax now in liquid form (though it wasn't in liquid form when he purchased it). The piece of wax now in liquid form acquired its present form by melting its past solid form (though its solid form wasn't acquired in that way). Thus the initial piece of solid wax became the liquified piece of wax, and didn't cease to exist 
in the process. Plausibly, then, the "two" pieces are in fact one and the same piece of wax.

Therefore, the initial piece of wax is identical to the puddle. ${ }^{1}$

What gives? More to the point, is the initial piece of solid wax identical to the wax puddle, or isn't it? I'll have more to say about this question in the discussion to come. Before we charge ahead, though, I'd like to outline a plan of attack.

In sections I-III I explain the dialectical significance of our little puzzle. Specifically, I argue that it puts a great deal of pressure on a certain kind of view about material reality, and I explain why there are no quick and easy solutions if one accepts the kind of view I'm targeting. For advocates of the target view, the puzzle is indeed a puzzle. If you think

\footnotetext{
${ }^{1}$ One might think that it doesn't follow from something's being a liquified piece of wax that it's a piece of wax, just as it doesn't follow from something's being a fake Rolex that it's a Rolex. Or one might challenge the inference from 'liquified piece' to 'piece' on the grounds that 'liquified piece' implies 'liquid', whereas 'piece' sans modifier implies 'solid'. Four points should be borne in mind, however. First, pointing out that something is a fake Rolex is a way of denying that it's a Rolex. In contrast, saying of something that it's a liquified piece of wax is not a way of denying that it's a piece of wax. Consider how odd it would be for me to challenge the truth of your claim that this thing here is a piece of wax by saying, "False! It's a liquified piece of wax." Insofar as there's a disagreement between us at all, I'm tempted to say it's metalinguistic: the consideration to which I appeal doesn't challenge the truth of your statement, merely the felicity of how it was expressed. This understanding of our hypothetical exchange is supported by the observation that it would have been a perfectly good response to your initial statement to say instead, "I agree, though I would just add that it's a liquified piece of wax." So the inference from 'liquified piece' to 'piece' is crucially different from 'fake Rolex; therefore, Rolex'. Second, it's a popular misconception that glass is a liquid-so popular, in fact, that Scientific American devoted an article to debunking it (Ciara Curtin 2007). Although the full story about the thermodynamics of glass is far too complicated to adequately summarize in a footnote (Philip Gibbs 1997), the popularity of the misconception, and how it's typically corrected (not by conceptual analysis, but by more information), indicates that the thought, Glass is a liquid, is merely an empirical falsehood. Even those of us who once thought that glass is a liquid had no problem with the phrase, 'piece of glass'. In other words, some of us once thought that pieces of glass are liquid pieces of matter, and we weren't conceptually confused in thinking so; we were simply ignorant. Consequently, 'piece' sans modifier doesn't imply 'solid'. Third, even if we grant that 'piece' sans modifier implies 'solid', the whole puzzle can be reformulated in terms of 'bit', as in 'the bit of wax', etc. It's absolutely unproblematic to say, 'I drank the bit of water', which clearly indicates that a bit of something may well be liquid. Now imagine we have some ice. Well, the ice is a bit of solid water. If melted, we obtain a liquified bit of water; and a liquified bit of water is indeed a bit of water. Similarly, a liquified bit of wax is a bit of wax. Corresponding adjustments to my Thesis and Antithesis would generate our puzzle, though it would require an unhappy change to my title. Finally, even if the objection stands, the central claim under Antithesis is left intact, namely, that the initial piece of solid wax became the liquified piece of wax, and didn't cease to exist in the process. As long as this claim is left unchallenged, we arrive at the puzzling conclusion. I'll have more to say about the central claim under Antithesis in the discussion below.
} 
you've already hit on a response that affords a quick and easy solution, I ask that you bear with me for the nonce.

In section IV I explain the theoretical significance of our little puzzle. In particular, I argue that our ordinary modal thought and language is too messy to be metaphysically probative without some degree of disciplinary intervention. This theoretical point is an old one, ${ }^{2}$ but I hope to present a more persuasive case for it. If sound, then we should expect our theorizing about modality to be more or less rationally reconstructive, by which I mean that an analysis deserves to be regarded as an adequate interpretation of ordinary modal thought and language, not because it vindicates all or even many of our ordinary modal beliefs, assertions, and patterns of reasoning (though hopefully it won't do too poorly on this count), but because it enables us to achieve many of the legitimate purposes for which we use modal concepts and terms. Achieving these purposes needn't require that our one-off modal judgments and patterns of thought be sound. It doesn't even require that large fragments of our ordinary ways of thinking be accurate. No doubt theorists can disagree about what our "legitimate" purposes are in this context, and I certainly won't say anything conclusive about the matter, but for the sake of concreteness I will identify one or two purposes that seem to me to be especially important. To put the point in a somewhat different and increasingly popular way, interpretations of modal thought and language should be ameliorative, not explicative. $^{3}$

I conclude in section $\mathrm{V}$ by returning to the original question-is the initial piece of solid wax identical to the wax puddle, or isn't it?-and spelling out what I suspect the correct answer is. I'd like to emphasize, though, that my dominant attitude is one of puzzlement, not confidence. This will be apparent in the tone I take, if not what I say.

${ }^{2}$ It is, I think, one way of interpreting Quine's famous argument involving the person who's both a mathematician and a cyclist. The mathematician is alleged to be necessarily rational but not necessarily two-legged; the cyclist is alleged to be necessarily two-legged but not necessarily rational. We're told that neither description allows us to represent this person's essence any better than the other. So quantified modal logic, and the essentialism it requires, is problematic, because it involves "an invidious attitude toward certain ways of uniquely specifying [things] and favoring other ways... as somehow better revealing the 'essence' of the object" (W. V. Quine 1953, p. 155; 1960, p. 199). The problems with this argument are well known, so I won't linger (Kit Fine 1989; David Kaplan 1986; Saul Kripke 1980).

${ }^{3}$ See Sally Haslanger (2012). 
To better understand the significance of our little puzzle-in particular, how it differs from the more familiar sort of case that guides theorizing about material identity and constitution-let's quickly compare it to Allan Gibbard's classic example, Lumpl and Goliath:

I make a clay statue of the infant Goliath in two pieces, one the part above the waist and the other the part below the waist. Once I finish the two halves, I stick them together, thereby bringing into existence simultaneously a new piece of clay and a new statue. A day later I smash the statue, thereby bringing to an end both statue and piece of clay. The statue and the piece of clay persisted during exactly the same period of time.

Here, I am tempted to say, the statue and the piece of clay are identical. ... If indeed the statue and piece of clay are the same thing, then their identity is contingent.... the statue I shall call 'Goliath'; the piece of clay, 'Lumpl'. (Gibbard 1975, p. 191)

I agree with Gibbard's judgment about this case, ${ }^{4}$ but not everyone does. Many philosophers have drawn a different conclusion, according to which Lumpl and Goliath are numerically distinct despite their spatiotemporal coincidence. Advocates of this view, or pluralists, say that Lumpl merely "constitutes" Goliath. ${ }^{5}$ More generally, pluralism is the doctrine that spatiotemporal coincidence doesn't entail identity. As one might expect, then, monism is the thesis that spatiotemporal coincidence entails identity. A particularly extreme form of monism is that spatial coincidence by itself entails identity. Gibbard, however, is a moderate monist; he believes that, in the absence of temporal coincidence, a statue (of an elephant, say) and its constituent hunk of matter will have different

${ }^{4}$ I've explained why elsewhere. See Mahrad Almotahari (2014a; 2014b; 2017; 2019). See also David Lewis (1971) and Delia Graff Fara (2012).

${ }^{5}$ See Lynne Baker (2007), Simon Evnine (2016), Kit Fine (2003; 2006; 2008), John Hawthorne (2008), Mark Johnston (1992; 2006), Daniel Korman (2015a), Kathrin Koslicki (2008), Thomas Sattig (2015), Judith Jarvis Thomson (1983; 1998), Amie Thomasson (2007), David Wiggins (2001), and Stephen Yablo (1987; 2015). 
temporal properties, such as "the property of being elephant-shaped as long as it exists" (1975, p. 190). Pluralism, too, has a more extreme relative, according to which not even necessary spatiotemporal coincidence entails identity. ${ }^{6}$ For the most part, I'll ignore the extreme variants of each thesis.

Pluralism is typically conceived as part of a larger Aristotelian framework, ${ }^{7}$ appropriately dubbed hylomorphism, according to which being (ov̉oia, ousia) is somehow constituted by both matter (ü $\lambda \eta$, hyle) and

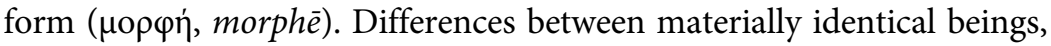
such as Lumpl and Goliath, are explained in terms of their form. The precise shape of the explanation varies from theorist to theorist, but in each case an appeal is made to a fundamental bifurcation whose history can be traced to Aristotle's remarks about form, matter, and their role in explanation. $^{8}$

Two different kinds of considerations are cited in favor of pluralism. The first kind is modal. Although Lumpl was destroyed when Goliath was smashed, things might have been different: Goliath might have been destroyed in a way that wouldn't have destroyed Lumpl-perhaps by squashing, or melting. According to this line of thought, Lumpl and Goliath are modally discernible and therefore numerically distinct. Approaching the matter from a somewhat different direction, the modal predications that allegedly distinguish Lumpl from Goliath rely on the thought that pieces of matter tolerate changes due to cohesion-preserving transformative processes. (Typically, the persistence of an artwork imposes different requirements.) Let's give this thought a name, to make discussion of it easier. Call it the transformative tolerance principle:

(TTP) Pieces of matter would survive cohesion-preserving transformations, if they underwent such a process. $^{9}$

6 Another view could be characterized as "extreme" pluralism, namely, what Karen Bennett (2004) calls plenitudinous primitivism. The two views are importantly different and shouldn't be confused.

7 See especially Simon Evnine (2016), Kit Fine (2008), Mark Johnston (2006), Kathrin Koslicki (2008), and Thomas Sattig (2015).

${ }^{8}$ See, in particular, Metaphysics Zeta.

9 Actually, I think TTP may need further refinement, but the additional complexity wouldn't change the shape of my argument; it would only delay its presentation. So I'll suppress any additional discussion. 
Although this principle is implicated in the pluralist's modal argument, it fundamentally specifies a condition on diachronic identity. And that's why it bears on our little puzzle, as I'll argue below.

The second kind of consideration in favor of pluralism is non-modal. For example, it's compatible with their complete spatiotemporal coincidence that Goliath is badly made for a thing of its kind, while Lumpl isn't. Gibbard could stipulate that Lumpl and Goliath don't differ in this particular way, but it doesn't really matter. We could go fishing for another non-modal difference: Goliath represents the infant Goliath but Lumpl doesn't; Goliath is Romanesque but Lumpl isn't, etc. Take your pick. ${ }^{10}$ Given that we're interested in artifacts and pieces of matter for different reasons, pluralists are reasonably confident that a categorical difference is inevitable. For the sake of argument, though, let's stack the deck in favor of the pluralist by reimagining Gibbard's example so as to make it seem that the dyadic predicate, '__ was made by __, can be filled in to distinguish Goliath from Lumpl. One might initially think this can't be done, given that Lumpl and Goliath begin to exist at precisely the same time, but I think it can. And seeing that it can will be quite useful later in this section.

Suppose that two smaller pieces of clay are each connected to the arms of two separate mechanical devices. For mnemonic (certainly not stylistic) reasons, call these devices The Lumper and The Shaper. Each device operates independently of the other. When The Lumper is turned on, it pushes the two pieces of clay together, eventually forming a single and comparatively large lump of clay. When The Shaper is turned on, it begins to mold the two pieces of clay so that one represents the lower half of the infant Goliath and the other the upper half. Now suppose you press the button that initiates The Shaper. Some time passes. I then press the button that starts The Lumper. Now suppose that the two devices complete their tasks at precisely the same time, and let 'Goliath' name the resulting statue and 'Lumpl' the new lump of clay. Finally, suppose that an hour later Goliath is smashed, destroying both statue and lump simultaneously. We thus have complete spatiotemporal coincidence. But, plausibly, Goliath was made by The Lumper and The Shaper

10 See Fine $(2003 ; 2006)$. 
collectively, though Lumpl wasn't; it was made by The Lumper alone. ${ }^{11}$ (Or, if you're reluctant to say that a mechanical device can make anything, perhaps because making is essentially intentional, then plausibly Goliath was made by you and me collectively, though Lumpl wasn't; it was made just by me.) According to the pluralist, then, the mere fact that Lumpl and Goliath share the same matter for the same period of time is perfectly compatible with a difference in origin-in one sense of the word, 'origin', which I will isolate with the phrase, 'origin-as-maker'. ${ }^{12}$ Generalizing the point, we might say that material identity is compatible with non-modal (that is, categorical) differences. ${ }^{13}$ We thus obtain the categorical contrast principle:

(CCP) Sameness of matter is compatible with categorical (that is, non-modal) differences.

This principle isn't restricted to synchronic applications. But not just any categorical difference over time makes for material non-identity. For example, Lumpl might be spherical and then cubical. A change in shape over time is consistent with being Lumpl throughout. So the applicability of CCP in an argument for the non-identity of things at different times requires that one select the right sort of categorical difference. Plausibly, a difference in origin is of the right sort.

I believe that TTP and CCP conflict. Our little puzzle about Descartes's puddle makes the conflict explicit. Have another look at the reasoning under Thesis. The initial piece of wax and the puddle are materially identical. They're made from the same matter. But, given CCP, they can differ in certain non-modal respects. My story ensures that this possibility is realized in Descartes's study, and it's realized in a way that supports non-identity: the piece and the puddle differ with

\footnotetext{
11 A monist might reasonably challenge this claim; for on her view Lumpl and Goliath are numerically identical. But on what plausible basis might a pluralist reject it?

${ }^{12}$ Evnine (2016) distinguishes between origin-as-matter and origin-as-act.

${ }^{13}$ Often enough, the term, 'categorical', is used for properties whose possession by a thing is determined by the way the thing is or was, as opposed to the way it would or could have been. The various ways the thing would or could have been are its hypothetical properties. The categorical/hypothetical distinction is to modality as the occurrent/non-occurrent and intrinsic/ extrinsic distinctions are, respectively, to time and space (Yablo 1992).
} 
respect to who made them and how they were made. So, anyone inclined to think that Lumpl and Goliath are distinct because of a non-modal difference between them ought to conclude, by parity of reasoning, that the piece and the puddle are distinct too. In fact, the non-modal considerations under Thesis are identical to the non-modal considerations for distinguishing statue and lump that Jeffrey King (2006, p. 1057, n. 52) attributes to Timothy Williamson. I don't know whether Williamson endorses those considerations, or whether he's a pluralist, but the parallel is interesting. Furthermore, King indicates that these considerations, which rely on the predicate, '__ was made by ___, are more worrisome for monists than arguments involving 'well made', 'Romanesque', and 'represents'. The reason is that they don't seem to involve any of the familiar sort of inference-undermining phenomena (gradability; conversational implicature; referential opacity) that seem to vitiate the other arguments.

Now have another look at the reasoning under Antithesis. The crucial step is the claim that the initial piece of solid wax became the liquified piece of wax, and didn't cease to exist in the process. To be absolutely explicit, the rationale for this claim is that the transformative process (melting) left intact the cohesion of the underlying matter. But this is merely an application of TTP, with which pluralists justify the nonidentity of Lumpl and Goliath. In our little puzzle, however, consistency requires that pluralists treat TTP as a reason to identify the piece and the puddle. But that yields an explicit contradiction, since we concluded earlier that the piece and the puddle are distinct. Thus, our puzzle brings into conflict the considerations that are cited in support of pluralism. The onus is on the pluralist to explain how her take on Lumpl and Goliath can withstand this conflict.

One might think that TTP should be understood, not as a universal generalization, but as a generic truth (e.g., 'Ravens are black' (but albinos aren't); 'Dogs have four legs' (but unfortunate specimens don't); 'Sea turtles are long-lived' (though the vast majority die young)). The potential worry is that, if TTP is a generic truth, then it doesn't necessarily apply to the situation in Descartes's study, and therefore doesn't justify the reasoning under Antithesis.

I'm confident that our little puzzle can't be dissolved by appeal to genericity. Generic truths are exception-tolerant generalizations as long 
as the exceptions are somehow abnormal or unsystematic (Bernhard Nickel 2016). Linguists and philosophers disagree about how to properly analyze the relevant notion of normality or systematicity. Is it statistical (Ariel Cohen 1999), normative (Michael Thompson 2008), or nomological ${ }^{14}$ Could it be altogether psychological, and not the sort of phenomenon that calls for a metaphysical account (Sarah-Jane Leslie 2008)? Let the chips fall where they may. There's nothing abnormal or uncharacteristic about the transformative process that occurs in Descartes's study. What I've described is an ordinary case of melting, relevantly like any other boring case of melting. If my little story presents an exception to TTP, it's not the benign sort which is compatible with generic truth; it must be a genuine counterexample. So, for my purposes, it doesn't matter whether TTP is generic or universal in form.

\section{II.}

One might be tempted to think that our little puzzle has an easy fix-so easy, in fact, that it might seem perverse for me to have presented the problem with all of the fuss and fanfare of a genuine philosophical conundrum. After all, it seems as though the conflict between TTP and CCP would be resolved if the pluralist simply rejected one kind of consideration in favor of non-identity. She might choose to embrace TTP and the modal contrast between Lumpl and Goliath but abandon CCP and the categorical differences between them. Or she might reject the modal contrast and decide that Lumpl and Goliath are distinct because of their inevitable categorical differences. Problem solved, right?

Wrong. TTP and CCP derive an equal measure of support from the same source, namely, pre-theoretical intuition. ${ }^{15}$ Neither exerts more intuitive pressure than the other, and each derives whatever epistemic

\footnotetext{
14 Thompson's view is not an analysis of generic statements per se, but a subclass of them that he calls "natural-historical judgments". It might be that genericity has a normative ground in some cases, a statistical ground in others, etc. However, if the phenomenon is too disjunctive, it may be less misleading to say there's no such thing as genericity.

15 See Fine (2003, p. 207; 2006, pp. 1069-70), Korman (2015a, pp. 204-5, n. 4), and Yablo (1987; 2015), all of whom accept the modal and non-modal considerations in favor of pluralism, emphasizing their intuitive appeal as weighty grounds for acceptance. Not one of these authors,
} 
authority it has from the intuitive pressure it exerts. Without some further story, plumping for one principle over the other would be entirely unmotivated and objectionably arbitrary. ${ }^{16}$ To be clear, my point isn't that a plausible story can't be told (although I'm highly skeptical, for reasons that will emerge momentarily). What I'm claiming, rather, is that one needs to be told. Otherwise, those of us who agree with Gibbard could reasonably reject both TTP and CCP, thus blocking the pluralist's challenge in one swift stroke. There's no advantage to being the more intuitive view if the intuitions promoting the view are both contradictory and on an equal footing, epistemically speaking. ${ }^{17}$

as far as I'm aware, gives any indication that they take one kind of intuitive consideration to be more or less epistemically secure than the other.

${ }^{16}$ Furthermore, why would it be unreasonable to draw a much stronger conclusion than the one I've been suggesting? In particular, what would be wrong with thinking that the little puzzle about Descartes's puddle undermines the reliability of our intuitions regarding the nature of material objects? There's a pleasing irony in this potential conclusion, since Descartes himself relied on a series of intuitive judgments about his wax to motivate the idea that the nature of matter is extension.

${ }^{17}$ It may be illuminating to compare the structure of my argument with Jennifer Saul's defense of a naive Russellian account of content, according to which (i) and (ii) express the very same proposition (see Saul 1997; 2007).

(i) Hammurabi believes that Hesperus is visible in the evening.

(ii) Hammurabi believes that Phosphorus is visible in the evening.

This commitment of the naive Russellian view is often considered to be highly implausible. To address the worry, naive Russellians have developed sophisticated ways of explaining how an utterance of (ii), on a particular occasion, might nevertheless convey different information from an utterance of (i) on that very same occasion, and how, on account of that difference in conveyed information, uninitiated language users intuitively (though incorrectly) judge that (i) and (ii) express different propositions (see Nathan Salmon 1986 and Scott Soames 2002). Many theorists take the naive Russellian's response to be inadequate (see, among others, William Taschek 1992). It is here that Saul's defense is relevant.

Abbreviating quite a lot, Saul argues that no one is in a better theoretical position than the Russellian, because we're all forced to tell a similar story-one in terms of a difference in conveyed information rather than a difference in proposition expressed-about (iii) and (iv):

(iii) Clark Kent went into the phone booth, and Superman came out.

(iv) Superman went into the phone booth, and Superman came out.

Saul's point is that if we're all in the uncomfortable position of having to tell such a story about (iii) and (iv) anyway, then it isn't so bad to extend that story to (i) and (ii). (This isn't quite right, in light of Saul (2007, ch. 6), but the subtlety can be ignored for the sake of brevity.) The upshot is supposed to be that considerations about the substitution of coreferential terms, contrary to popular belief, actually support naive Russellianism. Similarly, I've been arguing that we're all in the position of having to deal with the conflict between Thesis and Antithesis, which is structurally parallel to, and indeed motivated by, the intuitive considerations that are supposed to justify pluralism. Therefore, pluralists can't claim to be better off, dialectically, than their rivals. They are, in fact, worse off. 
In a brief exchange about our little puzzle, one respondent drew my attention to this passage from John Hawthorne (2008, p. 269), suggesting that it provides a principled reason to epistemically privilege the modal considerations over the non-modal, and thus to opt for TTP over CCP:

Turning to an example from the literature, it is true that 'That statue is well made' sounds acceptable while 'That lump is well made' sounds awkward (even in a case where the statue and lump come into existence at the same time). But notice that there is a similar contrast between 'That actress is well trained' and 'That person is well trained', but we hardly wish to infer from this that the actress is not identical to the person.

The Leibniz Law arguments from modal predication are much more powerful. Here we seem to have positive and conflicting modal intuitions about the statue/lump..., even in a case where their paths actually coincide. (Notice that while such sentences as 'The statue but not the lump is well made'... merely sound awkward and strange, the sentence 'The lump but not the statue could have survived crushing' sounds straightforwardly true. This is essentially why the Leibniz Law arguments from modal predication are more promising.)

I'd like to make three points in response.

First, it's unclear (at least initially) whether Hawthorne is making a psychological/dialectical observation or an epistemological one. What is clear is that Hawthorne takes one particular pair of non-modal considerations in support of pluralism to be "inconclusive", less "powerful", and less "promising" than arguments that rely on modal predication. I find myself wanting to ask, less promising for what, exactly? Presumably, for convincing the unconvinced. That sounds like a dialectical point to me. But a consideration in favor of some doctrine can be regarded as inconclusive, or less powerful, or less promising in virtue of the rules of

Much more could be said along these lines, and saying it, I believe, would only support my central argument. But it would require that we explore the literature on belief and belief ascription in the sort of detail that would only be of interest to an even narrower readership. For a discussion that's heavily influenced my thinking on these matters, see Richard Heck (2014). 


\section{MAHRAD ALMOTAHARI}

disputation and the background commitments of one's interlocutor, even though the consideration isn't in any worse epistemic standing for it. Recall, for example, Moore's response to the Cartesian skeptic: here is a hand, and here is another. Moore's argument seems not at all promising, from a dialectical point of view. Certainly no skeptic is likely to find it conclusive (nor, for that matter, are some non-skeptics) but the relevant consideration is, I believe, pretty well justified. It's epistemic standing, in other words, isn't diminished by its dialectical inefficacy. Are we to interpret Hawthorne as suggesting that the dialectical inefficacy of a certain non-modal predication is grounds for treating the corresponding claim as epistemically worse off? That strikes me as an uncharitable interpretation - uncharitable because obviously fallacious. If Hawthorne's point is dialectical and not epistemological, then it doesn't bear on my rationale for thinking that TTP and CCP are epistemically on a par.

But let's assume that Hawthorne's point in the passage I've quoted is epistemological and not merely dialectical. Still, it seems unable to provide an easy fix to our little puzzle. The reason is that-and here I'm offering my second response-even if Hawthorne is right about 'well made', he hasn't offered any reason at all to think that other non-modal predications are bound to be similarly problematic. It seems to me that the deck-stacking argument I presented earlier, in terms of the predicate, '__ is made by __, ' can't be dismissed as quickly as Hawthorne dismisses the argument in terms of 'well made'. And I'm not alone here; recall King (2006, p. 1057, n. 52), who shares Hawthorne's opinion about 'well made' but who explicitly acknowledges the force of arguments based on discernibility with respect to origin-as-maker (crediting Timothy Williamson with the observation). In any event, my point about the epistemic parity of TTP and CCP boils down to this: the claim that Lumpl would, but Goliath wouldn't, survive melting and the claim that Lumpl and Goliath differ with respect to origin-as-maker are equally well justified. And nothing that Hawthorne (or anyone else I'm familiar with) has said challenges that.

Third, the modal considerations in support of the pluralist's take on Lumpl and Goliath are, in a certain respect, weaker than the non-modal considerations. For the proper interpretation of modal speech and thought is no less controversial than the issue between the pluralist and 
her rival. And there are sophisticated techniques for analyzing modal claims so that they cohere with the identity of Lumpl and Goliath. Hawthorne criticizes these interpretive techniques because they rely on forms of context dependence that aren't paradigmatic. He recommends (and I agree) that these techniques are better thought of as "rational reconstructions" of our ordinary modal speech and thought, but he wonders "exactly what the motivation is supposed to be for the recommended departures from ordinary, natural ways of thinking. The burden certainly seems to be squarely on the [monist] to find a powerful motivation for it" (2008, p. 269). Fair enough; I'll take up this burden in section IV. What I want to do here is simply observe that the interpretive strategies that straightforwardly apply to the modal considerations seem not at all to get a grip on at least some of the non-modal considerations. Kit Fine (2003) argues for this point at great length. To that extent, then, some of the non-modal considerations are more powerful. Each kind of consideration has its strength and its weakness; I doubt one can definitively say whether one kind of consideration is in better epistemic standing than the other. ${ }^{18}$

I've been criticizing a response to our little puzzle that rejects CCP but maintains TTP. I know of no one who has rejected TTP while affirming CCP, but let's entertain the possibility for the sake of argument. A pluralist who opts for this response would no doubt want to maintain that Lumpl and Goliath are modally discernible, just not in the sort of way that an application of TTP would imply. Specifically, she would think that Lumpl, like Goliath, would not have survived melting, squashing, etc., but Lumpl could have existed without Goliath existing. This position strikes me as unstable. What justifies the thought that Lumpl could have existed without Goliath existing? Whatever the story may be-intuition? brute plausibility? conceivability? the intelligibility of certain why-questions? - a parallel story will surely apply to the thought that Lumpl, but not Goliath, would survive cohesion-preserving transformations. The challenge for the pluralist is to tell a story that doesn't

\footnotetext{
${ }^{18}$ Even if Hawthorne is right, so many prominent pluralists endorse both modal and nonmodal considerations that it would still be interesting to learn that there isn't enough room in logical space for this position to be occupied. For references, see n. 15.
} 
have this consequence-that doesn't treat the two sorts of modal judgments as epistemically on a par-but this challenge is of a piece with the original problem: to tell a story that explains why TTP and CCP don't enjoy the same epistemic standing. The new challenge is no less challenging, it seems to me, than the original one. And without an adequate response, the resulting position seems no less stipulative than plumping for one principle with no explanation at all. In short, our hypothetical critic seems not to have made any progress by opting for CCP over TTP.

The temptation to think that our little puzzle has a quick and easy fix is, I have found, hard to shake. Another way it manifests itself is in the thought, shared by some respondents, that the situation in Descartes's study can be given a consistent description. The details of the description don't really matter for now-though I myself offered one in the opening paragraph of this essay, and I'll consider another one in section III. What I want to emphasize, rather, is a valuable lesson that Kripke taught us in the context of a different puzzle, one about his fictional character, Pierre, and whether he does or doesn't believe that London is pretty. I've taken the liberty of streamlining Kripke's discussion, and substituting expressions that make it bear on our subject:

It is no solution in itself to observe that some other terminology, which evades the

[puzzle] may be sufficient to state all the relevant facts. I am fully aware that complete and straightforward descriptions of the situation are possible and that in this sense there is no paradox. . . . But none of this answers the original question. ... As in the case of the logical paradoxes, the present puzzle presents us with a problem for customarily accepted principles and a challenge to formulate an acceptable set of principles that does not lead to paradox, is intuitively sound, and supports the inferences [pluralists] usually make. Such a challenge cannot be met simply by a description of [the] situation that evades the question. (Kripke 1979, p. 147)

A consistent description of puzzling Pierre's situation doesn't, by itself, answer the question, does he or doesn't he believe that London is pretty? 
A fortiori, it doesn't answer the question in such a way as to reconcile the interpretive principles that Kripke relies on to generate an inconsistency. And, as long as it fails to do that, it fails to properly engage with Kripke's puzzle. Similarly, a consistent description of the situation in Descartes's study doesn't, by itself, answer the question, is the initial piece of wax identical to the wax puddle, or isn't it? A fortiori, it doesn't answer the question in such a way as to reconcile the principles that I rely on to generate an inconsistency. As long as it fails to do that, it fails to properly engage with my little puzzle.

We've looked at two allegedly quick and easy fixes. The first was premised on the suggestion that one of the two puzzling principles can simply be given up; the second on the thought that there are consistent ways of describing Descartes's study. I'll have more to say about this second strategy in section III, where I'll evaluate one detailed way of redescribing the situation. I'd like to close this section, however, by looking at a third consideration that might tempt one to think there's a quick fix, and hence no genuine puzzle for pluralists.

One might feel inclined to respond by pointing out that there are other ways of arguing for pluralism which don't require appealing to TTP. (I've encountered this reaction more than once.) For example, one might say that Lumpl could have existed even if Goliath hadn't. ${ }^{19}$ I wonder whether this thought really is all that different from TTP. After all, the thought is just an instance of the more general principle that pieces of matter could have existed even if the artifacts they constitute hadn't. This more general principle specifies an existence condition, just as TTP specifies an identity condition. It may be that material existence and identity are grounded in a common source, and that the clash between TTP and CCP is just as much a challenge for that more basic source from which TTP

\footnotetext{
19 One respondent suggested that the pluralist should rely on the thought that Goliath can survive the destruction of smallish parts, but the mereological sum of clay particles spatially coincident with it can't. This is, of course, the sort of argument with which Thomson (1983) begins her classic discussion. However, this response misses the point. Gibbard and Lewis are moderate monists; they already grant that Goliath and the mereological sum of clay particles with which it's spatially coincident are numerically distinct. Thomson's argument is no good against them. After all, Goliath and that mereological sum of clay particles aren't temporally coincident. What's at issue is whether one can argue against Gibbard and Lewis without relying on TTP.
} 
and the existential principle derive their truth or credibility. In any case, we needn't dwell on this possibility, because there's a deeper problem for the suggestion, namely, that it's completely beside the point.

Just imagine a similar response to Kripke's puzzle about belief: but the Fregean has other arguments for her view-arguments that are independent of substitution in belief contexts. ${ }^{20}$ Okay, sure, but does Pierre, or doesn't he, believe that London is pretty? Furthermore, are the interpretive principles (translation and disquotation) that give the question urgency coherent or not? The imagined response bears not at all on the central question of Kripke's puzzle. Similarly, the response we're now entertaining on behalf of the pluralist bears not at all on the central questions of our little puzzle. Is the initial piece of solid wax identical to the wax puddle, or isn't it? Are TTP and CCP compatible or aren't they? The response is, therefore, entirely unhelpful. ${ }^{21}$

${ }^{20}$ Recall that one of Kripke's stated aims in his classic discussion is to demonstrate that substitution arguments in terms of belief provide no support for Fregean theories of content. There are deeper problems about belief and belief ascription that everyone must face, and they're independent of the debate between Fregeanism and Russellianism.

${ }^{21}$ I can think of one more response on behalf of the pluralist. I'm reluctant to call this a "quick and easy" fix, since it relies on a highly controversial theory that not all of the pluralists within the blast zone of my bomb would be happy to grant, so I relegate discussion of it to this footnote.

Let a temporal profile be a function from times to occupied regions of space. Some pluralists believe that every temporal profile represents an existing object. On this view, there are many more things coincident with Goliath than just Lumpl. There's the statue-like object, Lefty, that ceases to exist when moved ever so slightly to the right but persists when moved ever so slightly to the left. There's also the statue-like object, Righty, that ceases to exist when moved ever so slightly to the left but persists when moved ever so slightly to the right. (There's a temporal profile that represents both Lefty and Righty.) Pluralists of this sort believe in a plenitude of entities. Recently, Shamik Dasgupta (2018) has relied on this plenitude to address the nonidentity problem in ethics. His proposal assumes that, sometimes, unbeknownst to us, our referring terms pick out some of the temporally fragile objects that we ordinarily ignore. I can imagine someone tempted by a similar thought $v i s-\grave{a}$-vis our little puzzle. Perhaps she might say that the phrase, 'the initial piece of wax', undergoes a kind of reference shift at some point that we fail to detect. Its referent in Thesis is something relatively fragile; its referent in Antithesis is something comparatively robust. So the identity that Thesis denies is compatible with the identity that Antithesis affirms.

If this proposal is sound, then why can't I detect a true reading of the sentence, 'The initial piece of solid wax is not identical to the initial piece of solid wax'? Furthermore, many sentences beginning with 'the initial piece of solid wax' would be semantically defective (either "gappy" or false), because the uniqueness presupposition would fail. But no such sentence, evaluated with respect to Descartes's study, sounds as bad to me as, say, 'The present king of France is bald'. In other words, the plenitude-lover is committed to there being a form of presupposition failure that's not at all paradigmatic. 


\section{III.}

Three points are worth bearing in mind. First, my puzzle about Descartes's puddle is not a mere repackaging of Gibbard's example involving Lumpl and Goliath. The pair of considerations that motivate the pluralist's take on Gibbard's case is the very source of my puzzle. Second, neither one of these considerations enjoys more plausibility, or greater intuitive appeal, than the other. They are, in short, epistemically equivalent. Rejecting one while holding onto the other would be an act of desperation. Finally, however the pluralist chooses to resolve this new little puzzle, her story had better satisfy an important dialectical constraint: it had better not undercut the rationale for treating Lumpl and Goliath as distinct. It might help to linger on this last point for a bit. I'll clarify what I mean here by considering a potential response to the puzzle that, I believe, violates the constraint.

One common reaction to the puzzle is that it somehow equivocates: Thesis encourages us to conceive of the piece and the puddle as artifacts, and, qua artifacts, they are discernible; Antithesis invites us to think of them as quantities of matter, or mere occupants of spacetime, and, qua matter, the piece literally became the puddle. If TTP is understood so as to apply only to quantities of matter, and CCP is interpreted to be about countable objects, such as artifacts, we obtain the beginnings of a story, or perhaps a redescription of my earlier story, that appears to resolve the inconsistency-a story or redescription according to which trouble arises from a failure to detect the underlying equivocation.

I say we have the "beginnings" of an account because the basic ideathat our puzzle exploits an illicit conflation-can, I believe, be worked out in a number of different ways. One way of working out the strategy involves the postulation of an ambiguity in the phrase, 'piece of wax'. Respondents often rely on this thought, but it seems to me to have very little going for it. It fails all of the tests for ambiguity that I'm aware of (Arnold Zwicky and Jerrold Sadock 1975; Adam Sennet 2016). For instance, the sentence, 'Pieces of wax are not pieces of wax', has no coherent reading. If 'piece of wax' were ambiguous, one would expect the sentence to have a coherent reading, just as the sentence, 'Bats are not bats', has a coherent reading. Of course, there may be subtle ambiguities 
that escape detection even by our most reliable linguistic tests. But these ambiguities aren't paradigmatic, and the pressure to acknowledge them should, I believe, come from theoretical demands internal to the empirical study of natural language. At any rate, pluralists often criticize monists for positing forms of context sensitivity or referential opacity that aren't paradigmatic (Fine 2003; Hawthorne 2008; Korman 2015a). It would be unprincipled to now rely on a form of ambiguity that displays the same theoretical shortcoming.

David Lewis considers a similar strategy in a different context. His criticism of it is relevant here: "I don't object to the strategy of claiming ambiguity. As you'll see, I shall defend a version of it. But it's not plausible to cook up an ambiguity ad hoc.... It would be better to find a widespread sort of ambiguity... and show that it will solve our problem" (1980, p. 230). ${ }^{22}$ One advantage of the monist-friendly response to the case of Lumpl and Goliath is that it identifies a widespread sort of

22 Another way of working out the equivocation strategy in detail yields a view called perspectival hylomorphism (Thomas Sattig 2015). This view takes to heart Obi-Wan Kenobi's advice to a certain boy from Tatooine: "Luke, you're going to find that many of the truths we cling to depend greatly on our own point of view." Abbreviating quite a lot, the view has two components. The first is that ordinary material objects are hylomorphic wholes (in some sense, compounds of matter and form). Second, speakers and thinkers employ two different "modes of predication" when speaking and thinking about ordinary material objects-a material mode of predication to speak and think about the material component of the hylomorphic whole, and a formal mode of predication to speak and think about the formal component. This view is noteworthy because it's tailor-made for pluralists. For a nice criticism of it, however, see Korman (2015b), who persuasively argues that there's no semantic or cognitive evidence for positing distinct modes of predication, and that even if there were distinct modes of predication, our actual intuitions can't be explained by reference to them.

A more radical way of implementing the equivocation strategy involves the idea of sameness/ difference in a respect: the piece is the same mass of wax as the puddle (Antithesis), but not the same artifact (Thesis); the appearance of a genuine puzzle is due to an illicit conflation of logically different identity claims. This implementation is no solution at all if the phrase, 'same $F^{\prime}$, is analyzable in terms of predication, absolute identity, and conjunction. For then we would obtain

Mass-of-Wax(the piece) \& Mass-of-Wax(the puddle) $\&$ the piece $=$ the puddle $\&$ Artifact(the piece) \& Artifact(the puddle) \& the piece $\neq$ the puddle

which is contradictory. The phrase, 'same $F$ ', must be understood as an unanalyzable unit, which carries a commitment to the doctrine of relative identity (Peter Geach 1962). There are numerous technical problems with this doctrine. For a survey of them, see Hawthorne (2003), in which the author concludes that "it is no mere artefact of philosophical fashion that Geach's relative identity approach has few adherents" (p. 23). But even if we conceive of these problems as research opportunities, and take the idea of relative identity to be understood well enough for use, the use of it here doesn't make much dialectical sense for a pluralist. There isn't any reason to apply it here while withholding its application from Lumpl and Goliath, in which case the whole motivation for pluralism would be undermined. More on this point to come. 
meaning variation (call it "ambiguity" if you like) in virtue of which the equivocation strategy can be more plausibly implemented. According to Gibbard and Fara, de re modal predications are, in general, sortalrelative; according to Lewis, the evaluation of a de re modal claim is always sensitive to a counterpart relation. Zoltán Gendler Szabó (2003) takes this sort of relativity a step further and suggests (albeit tentatively, it seems) that even non-modal predications are implicitly qualified, or semantically relativized, in a way that's compatible with Lumpl and Goliath's identity. Pluralists are reluctant to accept this widespread sort of meaning variation in their treatment of Lumpl and Goliath. They view the move as empirically objectionable, ${ }^{23}$ and dialectically confused. ${ }^{24}$ But if, in light of our new puzzle, a pluralist were now inclined to accept it, then the rationale for her treatment of Lumpl and Goliath would be undermined. For why should the pluralist not just embrace this reliance on sortal-sensitive evaluation a step sooner in the dialectic, thus taking Lumpl and Goliath to be identical, and the considerations that appear to militate against the identity to involve a similar kind of equivocation? If the pluralist concedes that predication is sensitive to a context-variable sortal or counterpart relation, which neutralizes the apparent tension between TTP and CCP, then how confident can she now be about her earlier assessment of Lumpl and Goliath? What reason has she to think that her take on Gibbard's case isn't similarly based on equivocation? An adequate solution to the initial puzzle shouldn't be self-undermining in this way. In particular, it shouldn't lend credence to the charge of $t u$ quoque.

\section{IV.}

So far, I've been arguing for the dialectical significance of our little puzzle. But I've also claimed that it has theoretical import. We're now in a position to say what the latter consists in.

\footnotetext{
${ }^{23}$ That is, it yields false semantic predictions (Hawthorne 2008; Korman 2015a, pp. 207-9).

24 "Philosophers of a monist persuasion have been content to show that we might talk as if their views were correct rather than that we actually do so talk" (Fine 2003, p. 202).
} 
Both TTP and CCP are modal claims, and the initial plausibility of each is revealed by ordinary modal thought about particular cases. Thus, our little puzzle entails that some of our ordinary modal judgments are inconsistent. What are we to make of this? I think it's reasonable to attribute the inconsistency we've uncovered to the inherently undisciplined character of ordinary modal thought. One response, then, would be to eschew modal concepts altogether. I regard this option as a massive overreaction. A more plausible response is to simply abandon the presumption against "revisionary" ways of understanding ordinary modal thought and speech. In particular, we should be open to interpretive projects, such as the sortal-relative semantics of Gibbard (1975) and Fara (2012), and the context-dependent counterpart theory of Lewis (1971), which arguably fail to accommodate certain ordinary modal claims but which impose a kind of rigorous flexibility on our modal thoughts and statements so as to render them coherent.

Of course, this sort of "revisionary" approach is subject to an important challenge that deserves a response: Why isn't a revisionary take on ordinary modalizing simply eliminativism in sheep's clothing? Jennifer Hornsby (2001) raises a version of this challenge quite explicitly. To help fix ideas and facilitate a clearer exposition of the issues, it will be useful to sharpen our formulation of the potential threat:

(1) Folk modalizing (the application of modal concepts and terms in ordinary speech and thought) is pluralistic about material reality. ${ }^{25}$

(2) So, whatever else they may be, analyses that purport to have modality as their subject, but which are not pluralistic, can't be theories of what folk-modal concepts and terms represent. ${ }^{26}$

(3) Modality is what folk-modal concepts and terms represent.

${ }^{25}$ Kit Fine (2003), John Hawthorne (2008), Eli Hirsch (2003), and Daniel Korman (2015a) defend this claim at great length.

${ }^{26}$ What justifies the inference from (1) to (2)? The thought is that any account of modality that isn't pluralistic will have to abandon too many platitudes about what would be, or what might have been, for the subject matter to be preserved. Taken individually, no one platitude makes the difference. I'm imagining an interlocutor who's sufficiently skeptical of the analyticsynthetic distinction, and who's savvy enough to acknowledge that the reference-fixing, or "metasemantic", story here is bound to be messy. 
(4) Therefore, analyses that purport to have modality as their subject, but which are not pluralistic, can't be theories of modality.

I don't know of any explicit formulation of this exact argument, but it strikes me as a more perspicuous statement of the worry that Kit Fine was voicing when he wrote, "Philosophers of a monist persuasion have been content to show that we might talk as if their views were correct rather than that we actually do so talk" (2003, p. 202). If Fine had something like the argument above in mind, then it would be clear why he takes the interpretive frameworks of Gibbard, Lewis, and Fara to be languages that differ from our actual modal language: these frameworks don't represent modality; they have an altogether different subject matter. ${ }^{27}$

I'm inclined to think that the inference from (1) to (2) is really quite bad and ought to be resisted. (Correlatively, any metasemantic theory that supports the inference from (1) to (2) is false.) The best way of demonstrating the mistake is by considering a parallel argument that's more clearly problematic in the relevant respect. ${ }^{28}$

Imagine someone who uncritically assumes that terms like 'parent', 'mother', 'father', 'son', 'daughter', etc., and the corresponding concepts, denote biological categories-they represent relationships that are grounded in the inheritance of genes. It wouldn't surprise me if many people actually believe something like this, nor would it surprise me if this sort of assumption controls patterns of use in speech and thought. For the sake of argument, let's say the assumption is widely shared and normatively influential. No doubt many parents of adopted children are

\footnotetext{
27 I think Nathan Salmon's harsh review of Lewis (1986) can be interpreted in the same way, though I won't pause to do so. See Salmon (1988, pp. 127-8).

${ }^{28}$ Let me acknowledge upfront that there are important substantive differences between the central argument about modality, (1)-(4), and the analogue argument about family kinds, (5)-(8). For example, I'm urging us to reject the former on broadly logical grounds, whereas the latter is problematic for ethical reasons. Furthermore, there seems to be a deeper tension between monism and pluralism than there is between biological and constructionist theories of family. (One can imagine a kind of contextualism to resolve the latter; in fact, at various points Haslanger seems sympathetic to such context sensitivity. Her view is certainly more nuanced than my brief characterization below suggests.) What matters for my purpose is not that there be a substantive analogy between the two arguments, but that there be a formal analogy between them, and that they both fail because the reference of our terms and concepts is partially determined by facts about the purpose for which we use them.
} 
made to feel awkward and uncomfortable by such assumptions on a regular basis. ${ }^{29}$ So there's an ethical reason to disrupt or critique the assumption. But suppose the person we're imagining tried to convince us that any modification to a biological understanding of folk family concepts and terms would merely change the subject. Coincidentally, this fictional character's imaginary argument looks rather familiar:

(5) Folk family classifications are biological.

(6) So, analyses that purport to have parenthood, motherhood, etc. as their subject, but which don't represent these relationships as being grounded in the inheritance of genes, can't be theories of what folk family classifications represent.

(7) Parenthood, motherhood, etc. are what folk family classifications represent.

(8) Therefore, analyses that purport to have parenthood, motherhood, etc. as their subject, but which don't represent these relationships as being grounded in the inheritance of genes, can't be theories of parenthood, motherhood, etc.

Given the prevalence of the belief that terms like 'parent', 'mother', 'father', 'son', 'daughter', etc., and the corresponding concepts, denote biological categories, and given the influence this belief has on patterns of use, denying (5) seems gratuitous. At any rate, we're supposing for the sake of argument that (5) is true. Moreover, (7) seems too plausible to credibly challenge. But-and here's the important point I've been building up to-we certainly aren't forced to accept an ethically objectionable understanding of family classifications. The reason, as Sally Haslanger (2006; 2012) has convincingly argued at length, is that enough of the legitimate purposes for which we encode family classifications in thought and language are served by an understanding of parenthood, etc. according to which parents are either primary caregivers or immediate progenitors that a change in one's understanding which represented parenthood

\footnotetext{
29 "my own experience as an adoptive mother has convinced me that at least in many contexts the dominant understanding of 'parent' frames it as a biological notion" (Haslanger 2012, p. 389-90).
} 
as (at least partially) a social classification would still deserve to be an analysis of parenthood. So, by merely acknowledging that we presently live in an unfortunate time when a certain assumption about the biological basis of family uncritically regulates the use of family classifications, we aren't committed to viewing alternative analyses of family notions as failing to be about what our folk classifications represent. In short, (5) doesn't entail (6). Here the rationale for treating an analysis of parenthood which fails to vindicate certain folk claims and patterns of reasoning as nevertheless having the same subject matter as the folk conception is based on the attractive thought that such an analysis would still serve the point of family classifications.

My suggestion is that the inference from (1) to (2) is problematic for a similar reason. Analyses of modal thought and language that are pluralistic may superficially appear to do better at accommodating a wider range of individual judgments and inferences, ${ }^{30}$ but if these patterns of thought turn out to be inconsistent, as I've argued they are, then such analyses do worse relative to perhaps the most important purpose of representation: coherent description. Coherence is a minimal requirement for truth and knowledge, and paradigm forms of representation (belief and assertion) aim at these values. It is in relation to truth and knowledge that the whole point of belief and assertion is defined. Insofar as "revisionary" analyses render folk modalizing coherent, and still enable us to achieve other legitimate purposes for which we modalize, they have a better claim to being about what folk-modal representations are about. What might some of these other purposes be? Foremost in my mind is an account of informational content, linguistic communication, and rational agency (Robert Stalnaker 1984; Frank Jackson 1994). Modal notions figure indispensably in such theorizing. Insofar as an understanding of necessity and possibility in terms of context-dependent counterpart theory, for instance, can satisfy these theoretical purposes, then it has a good claim to be a theory of modality. It isn't merely changing the subject. It would require a substantial amount of independent argumentation to convince me that an understanding of necessity

\footnotetext{
${ }^{30}$ For arguments to this effect, see Fine (2003), Hawthorne (2008), Hirsch (2003), and Korman (2015a).
} 
and possibility in terms of counterpart theory is incapable of satisfying these broader theoretical aims. I'm not saying it can't be done (but I will register my deep skepticism on this score); I'm saying that unless it's done, one can reasonably reject (2) while granting (1). And, of course, if such an argument were to succeed, then (1)-(4) would be otiose.

\section{V.}

You may have noticed that I haven't yet directly answered the question I keep incessantly asking: Is the initial piece of solid wax identical to the wax puddle, or isn't it? This is no accident. Philosophical problems are often more irritating than even the most promising responses are comforting. The problems have a way of lingering, dulled somewhat by the therapeutic treatment of an illuminating theory, but perennially threatening to flare up if the treatment is scrutinized. Why risk almost inevitable failure?

Be that as it may. I think I've said enough to hint at my preferred response, at least in outline: some form of monism, à la Gibbard, Lewis, and Fara, is probably right, and it ought to be applied here. Of course, the monist's treatment of our little puzzle doesn't involve any special pleading; it applies to both the piece and the puddle and to Lumpl and Goliath. I take this to be a theoretical virtue-one that pluralism lacks; for we ought to prefer theories that treat likes as likes. And it's my hope that the foregoing discussion has convinced you that the two issues-my puzzle and Gibbard's case-ought to be treated as likes. Furthermore, if the monist's treatment of these cases is based on considerations that are largely independent of the issues in this paper-for example, if she's a sortalist or counterpart theorist as part of a larger project to, say, vindicate a thoroughgoing Humeanism-then her application of the view doesn't merely accommodate our puzzle and Gibbard's case; it predicts the monist-friendly position. And predictive theories have an epistemic edge over theories that merely accommodate the phenomena. ${ }^{31}$ This means the

\footnotetext{
31 See Roger White (2003) on the epistemic advantage of prediction over mere accommodation.
} 
Ludovician package of metaphysical and semantic views derives an extra bit of support for its ability to handle our puzzle, since it's ultimately motivated by a Humean outlook (Lewis 1983). But I prefer to think in Ludovician terms primarily for autobiographical reasons (it was how I was raised), not because I'm a Humean. So I'll proceed accordingly.

CCP is, at bottom, a claim about possibility: it's possible that material objects with the same matter are categorically different. Insofar as this is true, it means that there's a way the world might have been such that if the world were that way, then artifactual counterparts of actual material objects would be categorically different despite having the same matter. Artifactual counterparts are objects that resemble each other along dimensions of resemblance appropriate for comparing artifacts (aesthetically, functionally, representationally, etc.). Applying this interpretation of CCP to the situation in Descartes's study, we arrive at the thought that, in the relevant way our world might have been (namely, the way it actually is), the piece and the puddle have artifactual counterparts (themselves) that differ with respect to origin-as-maker.

Now, interpreting TTP along similar lines, we obtain the principle that every way the world might have been (quantifier suitably restricted) is such that if the world were that way, then material counterparts of actual material objects would undergo a cohesion-preserving transformation and would survive. Material counterparts are objects that resemble each other along dimensions of resemblance appropriate for comparing matter (physically, mereologically, quantitatively, etc.). Applying this interpretation to Descartes's study, we're able to say that in all of the relevant ways our world might have been, the piece and the puddle have one and the same material counterpart: a single measurable quantity or mass of wax, conceived not as a countable individual but as a mere occupant of spacetime, which is identical neither to the artifactual counterpart of the piece in those ways nor to the artifactual counterpart of the puddle. ${ }^{32}$ (This is one of the chief virtues of counterpart theory: the counterpart

\footnotetext{
32 I'm assuming a "multiple-category" theory of masses (Dean Zimmerman 1995). If this sort of theory turns out to be false, then my little puzzle wouldn't be so little. It would pose a serious challenge to monists, as well, and we would all be forced to make some hard decisions. It's for this reason that I began the section with a pessimistic tone: I have no independent reason to be confident in the ultimate success of a multiple-category conception of masses.
} 
relation isn't transitive.) And this mass of wax does persist through the melting.

One more question deserves our attention. The story I just told grants that the piece and the puddle are distinct on the basis of a difference with respect to origin-as-maker. But the same kinds of considerations are at play in my reimagining of Gibbard's example about Lumpl and Goliath-what I earlier advertised as an argument that "stacks the deck" in favor of pluralism. How can a monist consistently say that, in our puzzle, these considerations entail non-identity, but that, in our reimagining of Gibbard's example, considerations of the same kind don't? Am I not more or less contradicting myself?

No, not if we extend counterpart theory to tensed, as well as modal, thought and speech (Hugh Chandler 1971). Consider, first, the claim that Goliath was made by The Lumper and The Shaper collectively. This means, roughly, that there's a time, $t$, earlier than the present such that The Lumper and The Shaper collectively make the artifactual counterpart of Goliath at $t$. But the artifactual counterpart of Goliath at $t$ just is the artifactual counterpart of Lumpl at $t$. (I am, after all, an avowed monist; I believe that Lumpl is Goliath.) So it mustn't be relative to the artifactual counterpart of Lumpl/Goliath that the claim, 'Lumpl wasn't made by The Lumper and The Shaper collectively', is evaluated; for if it were, the claim would be false. But it isn't false; it's true. The claim, 'Lumpl wasn't made by The Lumper and The Shaper collectively', must therefore be evaluated relative to some other counterpart, namely, the material counterpart of Lumpl/Goliath, which is just some mass of clay, not a countable individual. And it's true of the material counterpart of Lumpl/Goliath-a certain mass of clay-that, at $t$, The Lumper alone makes it. The difference, then, between the situation in Descartes's study and our reimagining of Gibbard's example is that, in the former, there are two artifactual counterparts relative to which the relevant claims are evaluated and, in the latter, only one relative to which the corresponding claims are evaluated.

My preferred response to our little puzzle about the piece and the puddle ends here. If I had a story to tell on behalf of the pluralist, believe me, I would tell it. But I don't. So I invite others to do better than I'm able. 


\section{Acknowledgments}

For their encouraging feedback and constructive criticism, I'm grateful to Karen Bennett, Min Buchanan, Aidan Gray, Mahmoud Morvarid, Bernhard Nickel, Will Small, Dean Zimmerman, and the anonymous reviewers for this volume of Oxford Studies in Metaphysics. I'm especially grateful to Min for the look of incredulity that prompted me to write $\mathrm{n} .1$.

\section{References}

Almotahari, Mahrad. (2014a). "Metalinguistic Negation and Metaphysical Affirmation.” Philosophical Studies 167: 497-517.

Almotahari, Mahrad. (2014b). "The Identity of a Material Thing and Its Matter.” Philosophical Quarterly 64: 387-406.

Almotahari, Mahrad. (2017). "Not' Again! Another Essay on the Metaphysics of Material Objects." Philosophy and Phenomenological Research 94: 711-37.

Almotahari, Mahrad. (2019). "Semantic Deflationism Deflated." Synthese 196: 2435-54.

Baker, Lynne. (2007). The Metaphysics of Everyday Life. Cambridge University Press.

Bennett, Karen. (2004). "Spatio-Temporal Coincidence and the Grounding Problem.” Philosophical Studies 118: 339-71.

Chandler, Hugh. (1971). “Constitutivity and Identity.” Noûs 5: 313-19.

Cohen, Ariel. (1999). "Generics, Frequency Adverbs, and Probability." Linguistics and Philosophy 22: 221-53.

Curtin, Ciara. (2007). "Fact or Fiction? Glass Is a (Supercooled) Liquid." Scientific American https:/www.scientificamerican.com/article/factfiction-glass-liquid/, accessed July 19, 2020.

Dasgupta, Shamik. (2018). "Essentialism and the Nonidentity Problem." Philosophy and Phenomenological Research 96: 540-70.

Evnine, Simon. (2016). Making Objects and Events. Oxford University Press.

Fine, Kit. (1989). “The Problem of De Re Modality.” In J. Almog, J. Perry, and H. Wettstein, eds., Themes from Kaplan. Oxford University Press, 197-272. 
Fine, Kit. (2003). “The Non-Identity of a Material Thing and its Matter." MIND 112: 195-234.

Fine, Kit. (2006). "Arguing for Non-Identity: A Response to King and Frances.” MIND 115: 1059-82.

Fine, Kit. (2008). “Coincidence and Form.” Aristotelian Society Supplementary Volume 82: 101-18.

Geach, Peter. (1962). Reference and Generality. Cornell University Press.

Gibbard, Allan. (1975). “Contingent Identity.” Journal of Philosophical Logic 4: 187-222.

Gibbs, Philip. (1997). “Is Glass Liquid or Solid?”, http://www.math.ucr.edu/ home/baez/physics/General/Glass/glass.html, accessed July 19, 2020.

Fara, Delia Graff. (2012). "Possibility Relative to a Sortal.” In K. Bennett and D. W. Zimmerman, eds., Oxford Studies in Metaphysics, Volume 7. Oxford University Press, 3-40.

Haslanger, Sally. (2006). "What Good Are Our Intuitions? Philosophical Analysis and Social Kinds." Aristotelian Society Supplementary Volume 80: 89-118.

Haslanger, Sally. (2012). Resisting Reality. Oxford University Press.

Hawthorne, John. (2003). “Identity.” In M. J. Loux and D. W. Zimmerman, eds., The Oxford Handbook of Metaphysics. Oxford University Press, 99-130. Reprinted in J. Hawthorne, 2006, Metaphysical Essays, Oxford University Press, 1-30. Page reference to this version.

Hawthorne, John. (2008). “Three-Dimensionalism Vs. Four-Dimensionalism.” In T. Sider, J. Hawthorne, and D. W. Zimmerman, eds., Contemporary Debates in Metaphysics. Blackwell, 263-82.

Heck, Richard. (2014). "Intuition and the Substitution Argument." Analytic Philosophy 55: 1-30.

Hirsch, Eli. (2003). “Against Revisionary Ontology.” Philosophical Topics 12: 51-73.

Hornsby, Jennifer. (2001). Simple Mindedness: In Defense of Naive Naturalism in the Philosophy of Mind. Harvard University Press.

Jackson, Frank. (1994). “Armchair Metaphysics.” In J. O’Leary-Hawthorne and M. Michael, eds., Philosophy in Mind. Kluwer Academic Publishers, 23-42.

Johnston, Mark. (1992). “Constitution is Not Identity.” MIND 101: 89-106. 
Johnston, Mark. (2006). "Hylomorphism." Journal of Philosophy 103: 652-98.

Kaplan, David. (1986). “Opacity.” In L. E. Hahn and P. A. Schilpp, eds., The Philosophy of W. V. Quine. Open Court, 229-89.

Korman, Daniel. (2015a). Objects: Nothing out of the Ordinary. Oxford University Press.

Korman, Daniel. (2015b). "Review of The Double Lives of Objects: An Essay in the Metaphysics of the Ordinary World by Thomas Sattig." Notre Dame Philosophical Reviews ndpr.nd.edu/news/the-double-lives-of-objects-anessay-in-the-metaphysics-of-the-ordinary-world/, accessed July 19, 2020.

King, Jeffrey. (2006). “Semantics for Monists.” MIND 115: 1023-58.

Koslicki, Kathrin. (2008). The Structure of Objects. Oxford University Press.

Kripke, Saul. (1979). “A Puzzle about Belief.” In A. Margalit, ed., Meaning and Use. Reidel Publishing, 239-83. Reprinted in S. Kripke, 2011, Philosophical Troubles: Collected Papers Volume 1, Oxford University Press, 125-61. Page reference to this version.

Kripke, Saul. (1980). Naming and Necessity. Harvard University Press.

Leslie, Sarah-Jane. (2008). "Generics: Cognition and Acquisition." Philosophical Review 117: 1-47.

Lewis, David. (1971). “Counterparts of Persons and Their Bodies.” Journal of Philosophy 68: 203-11.

Lewis, David. (1980). "Mad Pain and Martian Pain." In N. Block, ed., Readings in Philosophy of Psychology, Volume 1. Harvard University Press, 216-22. Reprinted in D. Rosenthal, ed.,1991, The Nature of Mind, Oxford University Press, 229-34.

Lewis, David. (1983). Philosophical Papers: Volume I. Oxford University Press.

Lewis, David. (1986). On the Plurality of Worlds. Wiley-Blackwell.

Nickel, Bernhard. (2016). Between Logic \& the World: An Integrated Theory of Generics. Oxford University Press.

Quine, W. V. (1953). From a Logical Point of View. Harvard University Press.

Quine, W. V. (1960). Word and Object. MIT Press.

Salmon, Nathan. (1986). Frege's Puzzle. Ridgeview Publishing.

Salmon, Nathan. (1988). "Critical Review of David Lewis, On the Plurality of Worlds." Philosophical Review 97: 237-44. Reprinted as "An Empire of 
Thin Air" in N. Salmon, Metaphysics, Mathematics, and Meaning: Philosophical Papers I, Oxford University Press, 122-8. Page references to this volume.

Sattig, Thomas. (2015). The Double Lives of Objects: An Essay in the Metaphysics of the Ordinary World. Oxford University Press.

Saul, Jennifer. (1997). "Substitution and Simple Sentences." Analysis 57: 102-8.

Saul, Jennifer. (2007). Simple Sentences, Substitution, and Intuitions. Oxford University Press.

Sennet, Adam. (2016). “Ambiguity.” In E. Zalta, ed., Stanford Encyclopedia of Philosophy https://plato.stanford.edu/entries/ambiguity/, accessed July 19, 2020.

Soames, Scott. (2002). Beyond Rigidity: The Unfinished Semantic Agenda of Naming and Necessity. Oxford University Press.

Stalnaker, Robert. (1984). Inquiry. MIT Press.

Szabó, Zoltán Gendler. (2003). “On Qualification.” Philosophical Perspectives. 17: 385-414.

Taschek, William. (1992). “Frege's Puzzle, Sense, and Information Content.” MIND 101: 767-91.

Thompson, Michael. (2008). Life and Action: Elementary Structures of Practice and Practical Thought. Harvard University Press.

Thomson, Judith Jarvis. (1983). "Parthood and Identity across Time." Journal of Philosophy 80: 201-20.

Thomson, Judith Jarvis. (1998). “The Statue and the Clay.” Nô̂s 32: 149-72.

Thomasson, Amie. (2007). Ordinary Objects. Oxford University Press.

White, Roger. (2003). “The Epistemic Advantage of Prediction over Accommodation.” MIND 112: 653-83.

Wiggins, David. (2001). Sameness and Substance Renewed. Cambridge University Press.

Yablo, Stephen. (1987). “Identity, Essence, and Indiscernibility.” Journal of Philosophy 84: 293-314.

Yablo, Stephen. (1992). “Cause and Essence.” Synthese 93: 403-49.

Yablo, Stephen. (2015). “A Thing and Its Matter.” In G. Rosen, A. Byrne, J. Cohen, and S. Shiffrin, eds., The Norton Introduction to Philosophy. W. W. Norton \& Company, Inc., 461-6. 
A little puzzle about A piece AND A puddle 261

Zimmerman, Dean. (1995). "Theories of Masses and Problems of Constitution.” Philosophical Review 104: 53-110.

Zwicky, Arnold and Jerrold Sadock. (1975). "Ambiguity Tests and How to Fail Them.” In J. Kimball, ed., Syntax and Semantics: Volume 4. Academic Press, 1-36. 